\title{
Effectiveness of traditional and online learning: comparative analysis from the student perspective
}

\author{
Elena Makarova* \\ Ural State University of Economics, Department of Business Foreign Language, 620144 \\ Yekaterinburg, Russia
}

\begin{abstract}
The article discusses challenges of effective learning in classroom and online environments from the student perspective. The aim of the study is to analyse university students' perception of advantages and disadvantages of digital education. The article presents comparative analysis of traditional classroom and online academic environments as viewed by first- and second-year Russian students majoring in management and economics. The study is a questionnaire-based research. Quantitative and qualitative research methods were applied to achieve study's objectives. Special attention was paid to the analysis of students' perception of a modern university teacher role in the classroom and online settings. The findings prove positive attitude of the respondents to digital learning and showed students' awareness of the barriers to effective distance learning, including their laziness and inability to concentrate. The research results can help practitioners and educators better understand students' learning needs and assist them in achieving academic success.
\end{abstract}

\section{Introduction}

Establishing a system of sustainable development in higher education has been declared as the aim of ENTEP Project [1]. This implies improving quality of education, which can only be reached by continuous professional development. Modern university teachers have to possess the ability to face new challenges arising from constantly changing teaching and learning environment, including digital transformation of education settings. These rapid changes have a serious impact on teachers working in higher education system. New academic reality and growing demands for highly professional graduates, who must be prepared to lead sustainable lifestyle, account for the necessity to redefine the role of a modern teacher [2]. Training students for working in digital economy, which is regarded as the main task of higher educational institutions today, demands developing teachers' ability to use digital technologies [3]. Digital competences of teaching staff can be trained in professional development programs [4], participation in which enables teachers to meet the growing demands of $21 \mathrm{st}$ century education.

\footnotetext{
* Corresponding author: makarovayn@mail.ru
} 
In spite of the fact that online education is rapidly increasing and growing, many problems remain unresolved. As a result, its challenges and issues continue to be in the focus of practitioners and researchers' attention [5]. Along with online education recognition, its disadvantages are widely discussed and debated [6;7]. Even though it is often the subject of criticism, there is no chance to get completely back to traditional learning and teaching. This inspires researchers and teachers to continue seeking practices which could help the improvement of online teaching and learning in the context of higher education [8]. Analysis of effectiveness of university distance learning is relevant as it promotes quality of education and enables students' academic success. Understanding of student's perception of the difference between traditional and online learning challenges can help identify students' needs and develop ways of improving teaching methods.

The key problem of online education in comparison to traditional learning and teaching is considered to be a lack of social presence [9]. Another issue that concerns most practitioners, is students' academic performance, their progress [10] and its evaluation in fulltime and distance study. Not sufficient research has been conducted in this field from student's perspective: "students' perceptions towards online learning as compared to traditional face-to-face learning have largely been overlooked" [11].

The aim of this paper is to examine Russian students' perception of traditional and online education processes. The objectives to achieve this aim are the following: to provide comparison of online learning to traditional one from student's perspective, to determine teacher's role online and in the classroom settings as seen by the students, to identify challenges and problems students face when learning at distance and in face-to-face class.

\section{Materials and methods}

A variety of methods were used to pursue the objectives of the study. Data were gathered by interviewing and surveying 38 Russian university students, who were required to answer 15 close-ended and open-ended questions. 28 of the respondents are first-year students majoring in economics, 18 are in their second year, their major is management. Quantitative and qualitative methods were applied for the data analyses.

\section{Results and discussion}

The questions of the survey concerned students' attitude to online and traditional forms of education; difficulties, they experience in distant learning, its advantages and disadvantages. The students also were asked about differences in teacher's role when teaching in the classroom and at distance.

$28.9 \%$ of the respondents answered that they preferred traditional learning and teaching. $26.3 \%$ of the students, which is quite close to the first group, chose online education environment as preferable. About half of the students (44.7\%) said they would be satisfied with combination of these two and preferred hybrid learning (Figure 1).

Hybrid education is considered an effective way and allows to combine traditional classroom activities, innovative teaching and learning techniques, and elements of digital education, depending on learning objective [12]. 


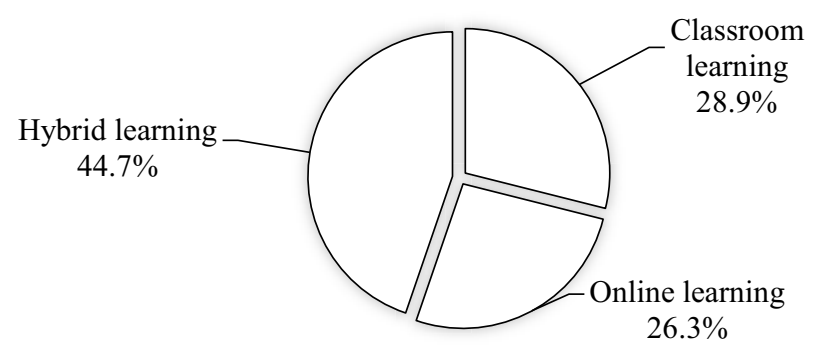

Fig. 1. Preferred forms of education

As viewed by the students, advantages of distance education in comparison to learning in traditional classroom settings are quite numerous. Saving time ranked first in this list. Over $80 \%$ of the respondents added that they live far from the university and learning at home or in the students' hostel help save not only their time but also money (transportation fare). The time which is saved this way, according to the respondents' answers, can be spent on sleeping longer and working (combining university studies with work). "Availability" and flexibility of learning ranked second: absence of necessity to be physically present in the classroom gives students a possibility to choose any learning setting, including outdoors. Extra time also helps the respondents plan their activities in most efficient way. $20 \%$ of the participants mentioned "comfort" as one more advantage of staying at home. Only $10 \%$ of the students' answers related to the description of advantages of educational process itself: online learning, in their opinion, implies extensive use of innovative informational and communication technologies, teacher's individual approach to student's needs and teaching creativity. Overall, the results prove positive perception of implementation of distance learning by the majority of the students, even though the reasons for such favourable attitude vary. About half of the students perceive distance learning as a process having no serious weaknesses. Some disadvantages of digital education, as seen by the rest of the respondents, include the following: learning material is difficult to understand, students are less involved in education process, there is a lack of direct teacher-student communication and students' socialization. About $20 \%$ of the respondents mentioned internet connection problems. Other disadvantages include insufficient technology skills of teachers, "screen fatigue" (tiredness of spending too much time in front of a computer) and a lack of motivation to learn.

Comparison of challenges and problems experienced in the classroom settings and learning online shows students' ability to analyse their academic performance and factors causing their low academic achievements. Among difficulties in online education about $20 \%$ of the students named their laziness and inability to concentrate and focus on the process of learning. Five students mentioned poor quality of internet connection, growing amount of homework in comparison to traditional learning, difficulties in material perception, a lack of teacher-student communication and absence of a possibility to ask their teacher a question. However, more than a half of the respondents experience no difficulties when learning at distance. Analyses of problems and challenges in the classroom settings showed correlation with the answers to the questions about advantages and disadvantages of learning in the classroom and online. Most students face no difficulties in the process of traditional learning. Anyway, some respondents complained of waste of time and money (getting to and back from university), a lack of enough sleep, and difficulties in combining work and studies.

Comparison of students' perception of the role of a university teacher in traditional and distance learning is given below. When answering the open-ended question about the role and functions of a modern teacher in the classroom, about $80 \%$ of the students named "teaching" and "transferring subject-related knowledge". The absolute majority of survey respondents wrote that they expected from their teachers "to teach well", "to teach in understandable way", "to explain in simple words", and "to give subject-related material in 
an interesting way". Two students chose such roles of a teacher as a "mentor" and a "tutor". Anyway, only $13 \%$ of the participants identified a teacher with a person who helps understand the material and answer students' questions, assists in solving problems, arising in the process of education, and communicates effectively. These data contradict students' perception of the qualities a university teacher must possess. Giving a portrait of a modern teacher, students concentrated on personal characteristics, describing personality traits rather than professional qualities, for example, patience, inspiration and willingness to inspire students, flexibility, creativity, frankness, sincerity, ability to admit mistakes, to understand students, and to communicate effectively, kindness, responsibility, sensitivity, and humanism. About $30 \%$ of the respondents mentioned usage of modern technologies as an essential skill for a modern teacher. When answering the question about teacher's ability to create effective classroom environment, more than $92 \%$ of the respondents confirmed teacher's power to improve classroom atmosphere. All the students agreed that a teacher can promote students' motivation to learn and encourage their involvement in education activities. Answers to these questions demonstrate, that in spite of perceiving a university teacher as a person who transfers knowledge, absolute majority of survey participants believe that an effective teacher should possess a certain number of personality traits. The study findings show that university teachers can have a considerable impact on student's academic success and development and increase motivation to learn. Connection between teacher power use and self-perception of learner empowerment is discussed in the article by A. Diaz, K. Kathryn and N. Karlyn [13]. Considering results of students' interviewing, the authors address the issues, answers to which are crucial for modern academic environment, for instance, what good and bad teachers do and what all teachers should know. The findings of the study show that teacher's reward power manifestations, such as being complimented by the teacher before classmates or receiving affirmations, are significant for student's academic progress. Among other strongest factors to motivate and promote student achievement, the authors name positive teacher-student relationships [14]. "Student pedagogical teams" are known to be an effective form to improve teacher-student cooperation [15]. Being engaged in this activity students can provide feedback on course content and structure as well as instructor performance. In this case students act as teachers' partners, and teachers get a tool to evaluate and improve quality of teaching.

$90 \%$ of the students consider that when teaching online a university teacher should perform the role of a transferer of subject-related knowledge. The answer "same as teaching in the classroom" was the most common. Among significant characteristics of online teacher, the respondents also listed strong computer literacy and ability and desire to involve every student in the process of learning. As for effectiveness of teacher-student interaction, $39.5 \%$ of the students would choose direct communication in the classroom, $15.8 \%$ would prefer to interact with their teachers online, $44.7 \%$ see no difference and consider, that way of communication has no significant impact on teacher-student interaction (Figure 2).

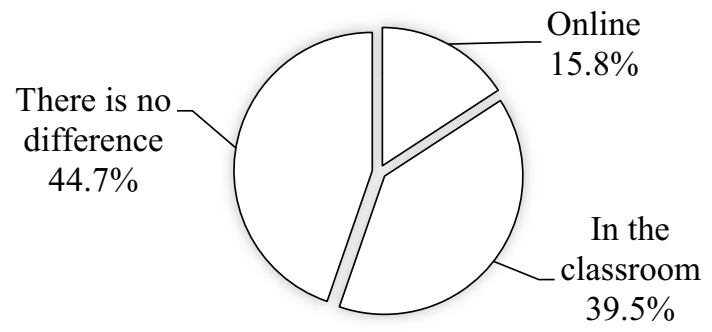

Fig. 2. Preferred forms of teacher-student interaction 


\section{Conclusion}

The results of the research show that majority of the Russian students, who participated in the study, have adapted to online environment and most would prefer keeping its elements in the future, combining classroom activities with distance learning. More than $50 \%$ of the respondents see no serious disadvantages in digital education in comparison to traditional teaching and learning. The same number of students do not experience difficulties in distance learning. Students' views on the effectiveness of distance education prove that they see no serious obstacles for making academic progress when learning online. The survey answers also show that the students perceive a university teacher as a transferer of subject-related knowledge and consider it to be the main role to perform both in the classroom and teaching online Among significant characteristics of online teacher, the respondents also listed strong computer literacy and ability and desire to involve every student in education process. At the same time, it is apparent that Russian students expect their teacher to combine professional and positive personal characteristics and skills.

More information on students' views about online education would help establish a greater degree of accuracy and better understand students' needs. Involving different groups of respondents, for example, third- and fourth-year students, who are more experienced in traditional classroom learning would enable more precise comparison of students' perception of digital learning. Further research needs to be done to compare students' and teachers' understanding of advantages and disadvantages of online education. Issue of students' responsibility for the results of their academic performance also looks promising for further study.

\section{References}

1. ENTEP Joint Project, https://entep-tudresden.de

2. I.E. Abramova, E.N. Makarova, Perspect Sci Educ, 44, 415 (2020)

3. G. Falloon, ETR\&D, 68, 2449 (2020)

4. İ. Reisoğlu, A. Çebi, Computers \& Education, 156, 103940 (2020)

5. S. Palvia, P. Aeron, P. Gupta, D. Mahapatra, R. Parida, R. Rosner, S. Sindhi, JGITM, 21, 233 (2018)

6. R. Fojtik, IJICTE, 7, 14 (2018)

7. N.A. Sokolova, A.A. Pylkin, O.A. Stroganova, K.G. Antonian, EpSBS, 51, 1478 (2018)

8. A. Sun, X. Chen, JITE: Research, 15, 157 (2016)

9. K. Kear, F. Chetwynd, H. Jefferis, RLT, 22, 1 (2014)

10. R. Fojtik, Procedia Soc Behav Sci, 182, 402 (2015)

11. F. Alsaaty, E. Carter, D. Abrahams, F. Alshameri, BMR, 5, 31 (2016)

12. H. Pratiwi, S. Sujito, H. Ayu, A. Jufriadi, ANCOSH, 1, 326 (2018)

13. A. Diaz, K. Cochran, N.J. Karlin, College Teaching, 64, 158 (2016)

14. S. Akhtar, M. Hussain, M. Afzal, S.A. Gilani, Eur Acad Res, 7, 1201 (2019)

15. L. Hayward, S. Ventura, H. Schuldt, P. Donlan, College Teaching, 66, 37 (2018) 